\title{
Reciclagem de clichês descartados da impressão flexográfica para produção de compósitos com aplicações para o isolamento acústico e térmico
}

\author{
Recycling of cliche waste from flexography printing \\ for production of composites with applications for \\ acoustic and thermal insulation
}

Elton Maciel ${ }^{1}$, Eduardo do Nascimento ${ }^{1}$

\author{
${ }^{1}$ Instituto Federal de Educação, Ciência e Tecnologia de Santa Catarina (IFSC) - Câmpus Caçador, CEP: 89503-550, Ca- \\ çador, Santa Catarina, SC, Brasil. \\ e-mail: eduardo.nascimento@ifsc.edu.br
}

\begin{abstract}
RESUMO
A flexografia é um método bastante utilizado na impressão de embalagens plásticas flexíveis, onde o clichê é uma placa de impressão resiliente fotopolimerizada. Os clichês são dificilmente reciclados, porque adquirem uma estrutura molecular reticulada, gerando também graves problemas ambientais no seu descarte final, logo que, apresentam um período de decomposição indeterminado. Consequentemente, as empresas precisam aterrar os clichês após o seu tempo de vida. Atualmente, não existem produtos ou métodos de reciclagem deste material. Portanto, o objetivo deste trabalho é reciclar os clichês descartados para a produção de placas para isolamento acústico e térmico. Desenvolveu-se um método de cominuição do material com uma adequada granulometria. As misturas feitas com clichê e PET triturado, prensados a uma temperatura de $350^{\circ} \mathrm{C}$, obtiveram uma elongação de $22 \%$ até a ruptura com alta flexibilidade. Adicionou-se até $90 \%$ de clichê reaproveitado nas composições estudadas. $\mathrm{O}$ isolamento térmico do compósito foi $18 \%$ inferior ao de um laminado de madeira com espessura similar. Em contrapartida, o isolamento acústico com as placas de clichê mostrou um aumento de $30 \%$ na capacidade de isolamento acústico, principalmente na faixa de frequência acima de $2 \mathrm{kHz}$, mostrando uma potencial aplicação para isolamento.
\end{abstract}

Palavras-chave: Reciclagem; Clichê; Flexografia; Isolamento térmico e acústico; Compósitos.

\begin{abstract}
Flexography is a widely used method in flexible packaging printing, where the cliche is a resilient photopolymerized printing plate. Cliches are difficultly recycled, because they acquire a crosslinked molecular structure. This also generates serious environmental problems in the final discard, as soon as, it has an indeterminate period of decomposition. Companies need grounding the cliches after their lifetime. Currently, there are no products or methods for recycling of this material. Therefore, the aim of this work is the recycle of cliche waste for the production of plates for thermal and acoustic insulation. A method of comminution of the material with suitable particle size was developed. Composites produced with cliche and PET by means of press molding at $350^{\circ} \mathrm{C}$, obtained high flexibility and elongation of $22 \%$ until rupture. Up to $90 \%$ of the cliche can be useful in the compositions studied. Thermal insulation of the composite was $18 \%$ lower than of a laminated wood plate with similarly thick. For other hand, acoustic insulation has increased by $30 \%$ with the composite plates, especially in the frequency range above $2 \mathrm{kHz}$, showing to a potential insulation application.
\end{abstract}

Keywords: Recycling; Cliche; Flexography; Thermal and acoustic insulation; Composites. 


\section{INTRODUÇÃO}

No atual contexto global, a sustentabilidade emerge como um princípio importante para a manutenção do sistema produtivo. Para atender esta demanda, a Política Nacional de Resíduos Sólidos, estabelecidas por meio da Lei Federal n ${ }^{\circ} 12.305$ de 02 de agosto de 2010, determina alguns princípios como: a gestão de resíduos que privilegie a ordem de não geração, redução, reutilização, reciclagem, tratamento e adequada disposição final dos rejeitos, o reconhecimento do resíduo reutilizável e reciclável como um bem e o incentivo à indústria da reciclagem. Por força legal, os geradores de resíduos sólidos indústriais precisam elaborar um plano de gerenciamento de resíduos sólidos, não obstante, é crescente a cobrança do mercado pelo cumprimento de normas de qualidade e de adequação ambiental das empresas. Assim, a utilização dos insumos em cascata é um método importante para a conservação de recursos, priorizando o gerenciamento hierárquico dos descartes [1].

Ao contrário do senso comum, a cadeia produtiva de reciclagem dos polímeros envolve ciclos e interações relativamente complexos, desde o descarte e coleta seletivos, até a existência de um mercado para o material reciclado. A reciclagem de polímeros pode ser classificada em três tipos: mecânica, química e energética. O processo conhecido como reciclagem mecânica consiste na combinação de um ou mais processos operacionais para o reaproveitamento do material descartado transformando-o em grânulos para a fabricação de outros produtos, aplicando-se ou não aquecimento. Na reciclagem mecânica as operações unitárias mais empregadas são a moagem e a extrusão, adicionalmente podendo ser utilizado o processo de aglutinação. A reciclagem química, consiste em um processo onde se realiza a conversão do resíduo plástico em produtos químicos básicos. Este tipo de reciclagem utiliza um meio de decomposição química, por exemplo hidrólise. É um processo de reações em solução, o qual geralmente, utiliza-se outros agentes químicos como catalisadores e reagentes. Por último, a reciclagem energética, consiste num processo de recuperação da energia contida nos resíduos através da sua incineração. A fim de, contribuir o mesmos possível para o efeito estufa, a tendência é reciclar ao máximo os materiais antes de incinerá-los $[2,3]$.

Santa Catarina tem a segunda maior produção nacional no setor de transformados plásticos. O estado possui três polos produtivos de transformados plásticos, sendo que, o terceiro maior deles localiza-se no meio-oeste, principalmente do segmento de embalagens plásticas. Na região meio-oeste, também estão instaladas dezenas de empresas de reciclagem $[4,5]$. A flexografia é um método de impressão rotativa direta para produção de embalagens plásticas que utiliza placas resilientes com imagens gravadas em relevo, chamadas de clichês. O clichê é formado por uma de resina à base de monômero metacrilato fotopolimerizável. Os clichês são dificilmente reciclados, porque adquirem uma estrutura molecular com ligações cruzadas após a fotopolimerização, gerando também, graves problemas ambientais na destinação final deste resíduo, pois, apresentam um período de decomposição indeterminado dada sua estabilidade química [6, 7].

Polímeros termoplásticos podem ser aquecidos, conformados, resfriados, novamente aquecidos e conformados por algumas vezes sem a perda significativa de suas propriedades físicas, porque possuem forças intermoleculares secundárias, sendo então, facilitada a sua reciclagem mecânica. Em algumas situações a reciclagem química também é viável. Por outro lado, polímeros termofixos possuem ligações cruzadas entre as suas cadeias, como é o caso do elastômero do qual é produzido o clichê. Estes são conformados por um processo de reticulação, ocorrendo ligações primárias entre as cadeias. Uma vez formadas estas ligações, não consegue-se conformá-los novamente via aquecimento, dificultando a sua reciclagem mecânica. Além disso, polímeros termofixos são insolúveis dificultando também processos químicos de reciclagem [2, 3].

Considerando as propriedades especiais necessárias para os materiais dos quais são fabricados os clichês, eles possuem relativamente alto valor tecnológico agregado. Apesar disso, as empresas de embalagens precisam descartá-los após terminar o seu tempo de vida útil. De acordo com estimativas realizadas em clicherias no município de Caçador, um conjunto de clichês para impressão de uma tiragem de embalagens pode custar aproximadamente $\mathrm{R} \$ 10.000,00$, dependendo da arte e da quantidade de cores. Há uma grande lacuna de trabalhos publicados na literatura sobre clichês para impressão flexográfica e, principalmente, sobre processos de reciclagem destes materiais. A redução na parcela do valor do clichê por embalagem fabricada pode ser significativa, ponderando que, os rejeitos de clichês deixam de ter custo adicional embutido no seu descarte final e passam a somar um valor agregado, se puderem ser adequadamente recuperados, proporcionando um incremento na competitividade das empresas e imensuráveis benefícios com a redução aos danos ambientais. É do nosso mais amplo conhecimento que não existe processo comercial ou trabalho publicado na literatura que apresente algum método de reciclagem de clichês. Portanto, o objetivo central deste trabalho é reciclar os clichês descartados pelas empresas de embalagens locais para produção de placa de isolamento acústico e térmico.

\section{MATERIAIS E MÉTODOS}

Os clichês utilizados neste trabalho foram doados por uma clicheria local. A partir disso, testou-se 3 técnicas para a cominuição dos clichês descartados. Primeiro, um ralador industrial com capacidade de 120 kg/h Rec-150 Becker, segundo, um macromoinho de facas tipo Willey Marconi MA340 e terceiro, um aglutinador Lessa 100 CV para reciclagem de plásticos com sistema de corte por rotor com 4 facas de giro e diâmetro do tambor $900 \mathrm{~mm}$. Após a cominuição o material particulado foi peneirado em uma malha 08 quando necessário a retirada de pedaços muito grandes, utilizando-se todo o material passante. 
Para produzir as placas de isolamento utilizou-se prensagem à quente. Os clichês foram moídos, misturado proporcionalmente com outro polímero termoplástico, adicionado em um molde e aquecido em um forno. Após determinado tempo de aquecimento, o molde foi retirado do forno e imediatamente prensado. Para isto, utilizou-se um molde metálico de 30 $\mathrm{cm}$ de diâmetro, um forno mufla com aquecimento até $1000^{\circ} \mathrm{C}$ e uma prensa hidráulica de 15 ton. Realizou-se a prensagem do clichê junto com polímero politereftalado de etileno (PET) triturado, seguindo o planejamento experimental disposto na tabela 1. Utilizou-se o PET triturado misturados manualmente em um recipiente com o clichê moído. De modo adicional, realizou-se a mistura do clichê moído com polietileno de alta densidade (PEAD) granulado por meio de uma extrusora de rosca simples AX Plásticos LAB-16. O material foi extrudado dentro do molde, depois disso, manteve-se o aquecimento no forno com subsequente prensagem. Neste caso, optou-se pela mistura com o processo de extrusão, devido à disponibilidade do equipamento. A extrusão do PET exigiria uma configuração do equipamento e de rosca especiais, as quais não se tinha disponível. No caso da mistura com PEAD via extrusão, o planejamento experimental seguiu a tabela 2.

Tabela 1: Composições e variáveis estudadas para a produção de placas por prensagem à quente.

\begin{tabular}{c|c|c|c|c}
\hline QTD. PET (g) & QTD. CLICHÊ (g) & TEMPERATURA FORNO ( $\left.{ }^{\circ} \mathbf{C}\right)$ & TEMPO FORNO (min) & $\begin{array}{c}\text { PRESSÃO } \\
\text { (ton) }\end{array}$ \\
\hline 15 & 35 & 250 & 5 & 5 \\
\hline 15 & 35 & 250 & 5 & 10 \\
\hline 15 & 35 & 250 & 5 & 5 \\
\hline 15 & 35 & 300 & 5 & 10 \\
\hline 15 & 35 & 300 & 10 & 5 \\
\hline 15 & 35 & 300 & 5 & 5 \\
\hline 15 & 35 & 350 & 5 & 10 \\
\hline 15 & 35 & 350 & 10 & 5 \\
\hline 15 & 35 & 350 & 10 & 10 \\
\hline 15 & 35 & 350 & 5 & 5 \\
\hline 5 & 45 & 250 & 5 & 10 \\
\hline 5 & 45 & 250 & 10 & 5 \\
\hline 5 & 45 & 250 & 5 & 5 \\
\hline 5 & 45 & 300 & 5 & 10 \\
\hline 5 & 45 & 300 & 10 & 5 \\
\hline 5 & 45 & 300 & 5 & 5 \\
\hline 5 & 45 & 350 & 5 & 10 \\
\hline 5 & 45 & 350 & 10 & 5 \\
\hline 5 & 45 & 350 & 350 & 5 \\
\hline 5 & 45 & & & \\
\hline
\end{tabular}

Tabela 2: Composições misturadas por extrusão e variáveis estudadas para a produção de placas.

\begin{tabular}{|c|c|c|c|c|c|}
\hline $\begin{array}{c}\text { QTD. } \\
\text { PEAD (g) }\end{array}$ & $\begin{array}{c}\text { QTD. } \\
\text { CLICHÊ (g) }\end{array}$ & $\begin{array}{l}\text { TEMPERATURA } \\
\text { EXTRUSÃO }\left(\mathrm{C}^{\circ}\right)\end{array}$ & $\begin{array}{c}\text { TEMPERATURA } \\
\text { FORNO }\left(\mathbf{C}^{\circ}\right)\end{array}$ & $\begin{array}{c}\text { TEMPO FORNO } \\
(\mathrm{min})\end{array}$ & $\begin{array}{c}\text { PRESSÃO } \\
\text { (ton) }\end{array}$ \\
\hline 10 & 40 & 200 & 250 & 5 & 5 \\
\hline 20 & 30 & 200 & 250 & 5 & 5 \\
\hline 30 & 20 & 200 & 250 & 5 & 5 \\
\hline
\end{tabular}

Para averiguar a resistência mecânica das placas, realizou-se testes de tração nos compósitos produzidos numa máquina de ensaio universal de tração EMIC-DL 2000 utilizando garras de pressão com uma velocidade de deslocamento de $10 \mathrm{~mm} / \mathrm{min}$. A deformação foi determinada pelo deslocamento da torre do equipamento, não sendo utilizado extensômetro devido à não normatização dos corpos-de-prova. Tiras de $3 \mathrm{~cm}$ de largura e $10 \mathrm{~cm}$ de comprimento foram cortadas das placas produzidas. A espessura das placas produzidas foi de aproximadamente $2 \mathrm{~cm}$. Cada corpo-de-prova teve suas dimen- 
sões medidas individualmente. Foram testados 10 corpos-de-prova das composições mais adequadas de composição e de processamento, conforme resultados e discussão.

Um aparato para medida do isolamento térmico foi construído, constituído de uma placa metálica aquecida por resistências. A placa de clichê com aproximadamente $2 \mathrm{~cm}$ de espessura foi colocada sobre a placa aquecida a temperatura de $150^{\circ} \mathrm{C}$. Após isto, mediu-se a variação da temperatura com termopares em função do tempo na parte superior da placa em 5 pontos distintos, como mostrado na figura 1a. A fim de, comparar o desempenho do isolamento térmico, realizou-se o mesmo teste com uma placa de madeira compensada de espessura similar à placa de clichê.

Para realizar os testes de isolamento acústico, construiu-se uma cabine de madeira com dimensões de $\quad 1,2 \mathrm{~m}$ x 1,2 m x 2 m, a qual foi revestida com as placas de clichê, como mostrado na figura 1b. Uma caixa de som amplificada com potência de $600 \mathrm{~W}$ rms foi utilizada para a reprodução de um som em diversas frequências. Por meio do software tone generator programou-se a mudança da frequência sonora emitida a cada 3 segundos, variando desde $200 \mathrm{~Hz}$ até $4200 \mathrm{~Hz}$. $\mathrm{O}$ intervalo de frequência foi escolhido de acordo com a capacidade da caixa de som. Foi utilizado um decibelímetro digital $30 \mathrm{~A} 130 \mathrm{~dB} / 0,1 \mathrm{~dB}$ AKSO-AK822 para realizar a medida da intensidade sonora. O decibelímetro foi colocado no interior da cabine e programado para gravar a intensidade sonora continuamente, em seguida, o som foi emitido na parte externa da cabina a $1 \mathrm{~m}$ de distância. O teste foi realizado na cabine sem isolamento e com isolamento das placas de clichês.

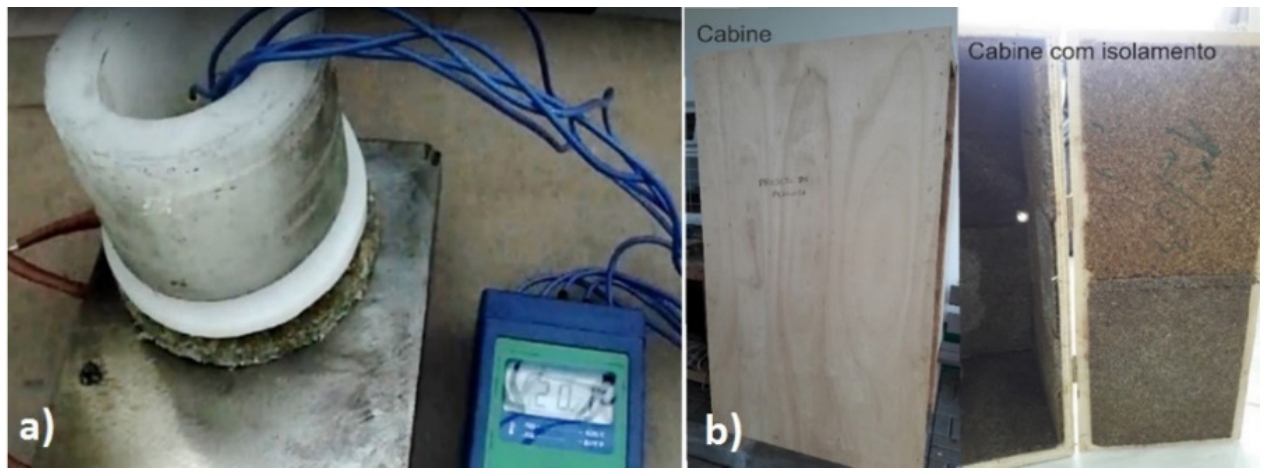

Figura 1: a) Aparato de medição do isolamento térmico com placa de aquecimento. b) Cabine construída para os testes de isolamento acústico.

\section{RESULTADOS E DISCUSSÃO}

O método de moagem com o ralador industrial produziu adequado tamanho do particulado de menor magnitude como visto na figura $2 \mathrm{a}$, no entanto, não houve êxito na obtenção de substancial volume de clichê moído por este método. Na cominuição com moinho de facas, o tamanho do particulado obtido não foi adequado para a produção das placas, sendo em média maior de $1 \mathrm{~cm}$ como observado na figura $2 \mathrm{~b}$. Apesar disso, o método foi bastante efetivo na velocidade de moagem e no volume de material moído. Por último, na cominuição com um aglutinador também obteve-se um adequado tamanho de partículas, como visto na figura 2c. Neste caso, foi necessário peneirar o particulado posteriormente, para retirada de pedaços maiores, mesmo assim, o volume de material passante na peneira produzido foi suficiente para a demanda de produção das placas de isolamento.

O particulado de clichê com o PET triturado foram misturados manualmente em um recipiente, dispostos no molde, aquecidos por determinado tempo e em seguida prensados. Como forma de avaliação da adesão do particulado nas placas produzidas, foi verificada a resistência das placas flexionando-as manualmente. Quando não houve adesão as placas, elas romperam ao serem minimamente manipuladas, ou senão, elas quebraram ao serem retiradas do molde. Através desta avalição qualitativa, averiguou-se as condições mais adequadas para a temperatura do forno, tempo no forno e pressão de compactação utilizados para a conformação dos compósitos. Isto é, as condições possíveis de se confeccionar as placas foram consideradas adequadas. Observou-se que, a pressão pouco influenciou na produção das placas. A temperatura do forno e o tempo em que o material foi deixado no forno tiveram maior influência na produção das placas com flexibilidade minimamente adequada para a sua retirada do molde e posteriormente, para sua manipulação. Na temperatura nominal do forno de $250^{\circ} \mathrm{C}$, o PET não amoleceu o suficiente para aderir ao clichê, mesmo deixando o material por 10 min no forno. A $300^{\circ} \mathrm{C}$ por $10 \mathrm{~min}$ ou $350^{\circ} \mathrm{C}$ por $5 \mathrm{~min}$ foram as condições que possibilitaram adequada compactação, retirada do molde e manipulação das placas. $\mathrm{O}$ material deixado nas condições de temperatura nominal do forno de $350^{\circ} \mathrm{C}$ e mantido por 10 min no forno sofreu degradação. Portanto, a condição considerada mais adequada para a produção das placas foi temperatura nominal do forno de $350^{\circ} \mathrm{C}$ mantido por 5 min no forno seguido por prensagem a 5 ton. Nestas condições, foi possível produzir de maneira íntegra as placas em ambas as composições testadas, com $70 \%$ e $90 \%$ de clichê reciclado. Então, op- 
tou-se por adicionar a maior quantidade possível de clichê no compósito com PET, ou seja, recuperando 90\% dos resíduos de clichê na confecção das placas. A temperatura e tempo ajustados dependem do tamanho do molde e forno disponíveis.

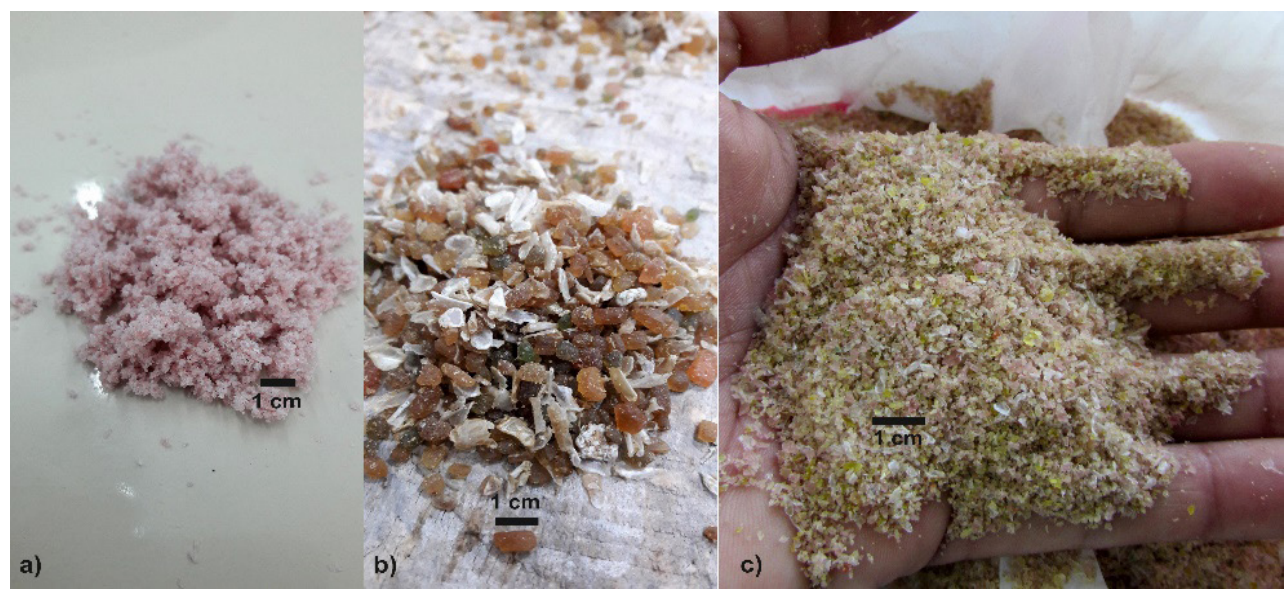

Figura 2: a) Particulado de clichê obtido por meio da cominuição com ralador industrial. b) Particulado de clichê obtido por meio da cominuição com moinho de facas. c) Particulado de clichê obtido por meio da cominuição com aglutinador.

De modo adicional, realizou-se a mistura do clichê com PEAD por meio de uma extrusora. Foi possível obter compósitos com PEAD, porém, com no máximo 60 \% de clichê na mistura. Na composição com $80 \%$ de clichês e 20\% PEAD misturados por extrusão, o material ficou quebradiço ao manipulá-lo, não sendo possível a produção das placas. Desta forma, o índice de recuperação do clichê com o PEAD é menor em comparação com PET, de acordo com os métodos testados. Logo que, não existem dados da literatura de compósitos de termoplásticos e clichês reciclados, destaca-se uma análise do ciclo de vida de compósitos de termoplásticos e madeira [8]. Nesta situação, nos compósitos feitos de plásticos virgens, quanto maior a quantidade de madeira reaproveitada, menores serão os potenciais impactos ambientais, sendo a alternativa ecológica e tecnológica mais adequada de acordo com os autores. Comparativamente, a maior quantidade de PEAD gasta no compósito, também deve inviabilizar a recuperação do clichê.

As placas produzidas precisam apresentar uma mínima resistência para sua aplicação. Por conseguinte, realizou-se testes de tração nos compósitos. Foram testados corpos-de-prova das composições julgadas mais adequadas: com $90 \%$ clichê e $10 \%$ PET conformada a $350^{\circ} \mathrm{C}$ por 5 min no forno seguido por prensagem a 5 ton, e, com $60 \%$ clichê e $40 \%$ PEAD misturados por extrusão, conformado a $250^{\circ} \mathrm{C}$ com prensagem a 5 ton. Os compósitos com PET tiveram uma elongação máxima de $22 \% \pm 8$ e uma tensão de ruptura de $1,7 \mathrm{MPa} \pm 0,6$. As placas produzidas com adequada flexibilidade são observadas na figura 3a. Por outro lado, os compósitos com PEAD tiveram uma elongação máxima de $5 \% \pm 3$ e uma tensão de ruptura de $0,8 \mathrm{MPa} \pm 0,3$. Isto ocorre devido à baixa afinidade do clichê, fotopolímero à base de metacrilato (polar) com o polietileno (apolar). A figura $3 \mathrm{~b}$ mostra um corte transversal nas placas indicando as porosidades presentes no compósito com PET, fato que, correlacionado à maior resistência à tração desta composição, indica maior adesão entre clichê e PET. Estes dados devem ser interpretados de modo comparativo, logo que tais testes são relativos, pois os corpos-de-prova utilizados não seguem padronização da norma técnica. Devido à isto os desvios são elevados, mas, ainda assim, a variação entre as composições pode ser considerada significativa. Exemplos da curva tensão-deformação para as composições estudadas estão dispostas na figura 4.

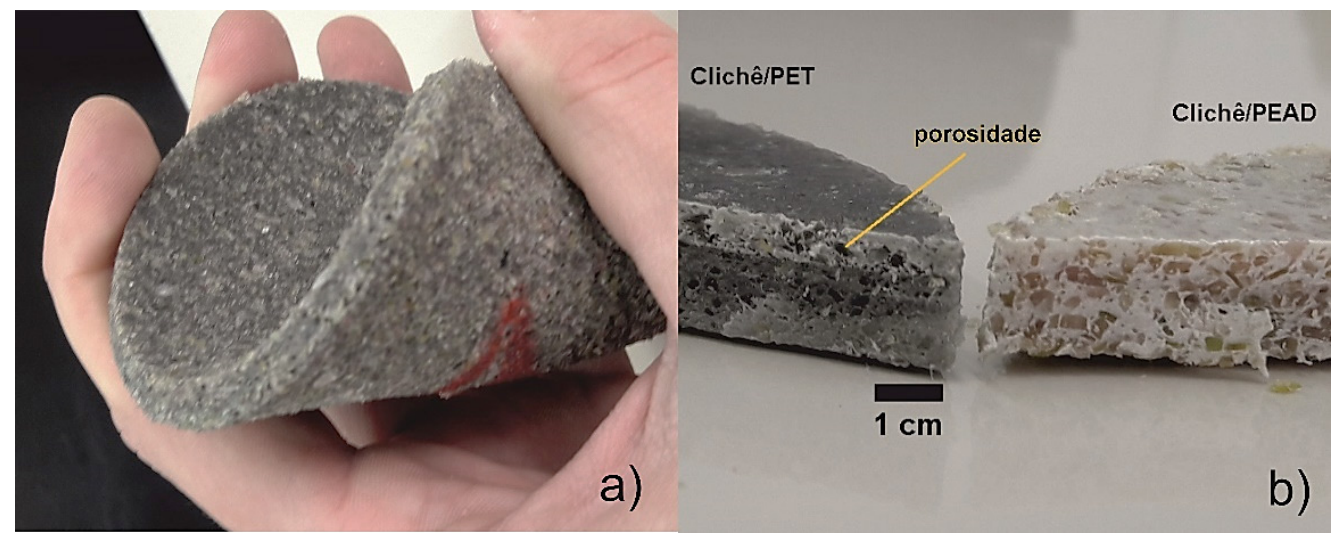

Figura 3: a) Placa de compósito com alta flexibilidade, composição $10 \%$ PET e $90 \%$ clichê triturados prensado à quente. b) Corte transversal nas placas de compósitos indicando as porosidades no compósito com $10 \%$ PET e $90 \%$ clichê e compósito $60 \%$ clichê e $40 \%$ PEAD misturados via extrusão. 


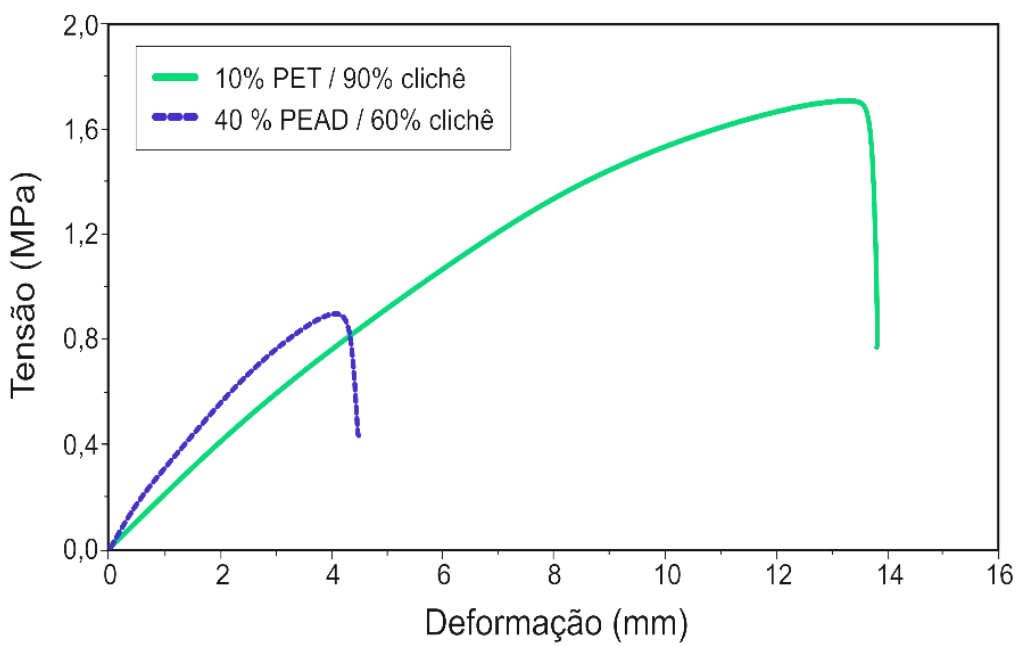

Figura 4: Curva tensão-deformação para os compósitos com clichê reciclado. Dimensões do corpo-de-prova $3 \mathrm{~cm}$ x $2 \mathrm{~cm}$ x $10 \mathrm{~cm}$ e velocidade de deslocamento de $10 \mathrm{~mm} / \mathrm{min}$.

Os resultados sobre isolamento térmico são mostradas na figura 5. O compósito PET/clichê produzido tem menor capacidade de isolamento térmico em comparação com uma placa de madeira laminada de espessura similar. Enquanto que, no início da região assintótica da curva de variação da temperatura (Fig. 5), a placa de madeira apresenta uma temperatura de aproximadamente $55^{\circ} \mathrm{C}$, a placa de clichê mostra uma temperatura em cerca de $67^{\circ} \mathrm{C}$. Além disso, a difusividade térmica na placa de clichê é maior, visto que, a temperatura aumenta mais rapidamente no compósito. A menor capacidade de isolamento térmico que a madeira também pode estar relacionada à volatilização de resíduos de solventes e umidade, o que pode ter aumentado a difusão do calor através do material. Apesar disso, a placa de clichê tem adequada capacidade de isolamento térmico, visto que, comparativamente a madeira laminada tem alta capacidade de isolamento térmico. Esperava-se ser capaz de melhorar o desempenho das placas de clichê, no entanto, adicionais testes, secando o material antes das análises, precisam ser realizados para aprimorar o resultado encontrado. O compósito clichê e PEAD não pode ser testado em tais condições, pois o PEAD funde em contato com a placa de aquecimento a $150{ }^{\circ} \mathrm{C}$.

Como os dados sobre clichês na literatura são limitados, um material com aplicações similares às propostas para o compósito com clichê, é a manta de isolamento térmico de poliéster, as quais são comumente produzidas de material reciclado [9]. Fibras de PET apresentam um adequada capacidade de isolamento térmico, similar à lã e à madeira, sobretudo podem ser misturadas com fibras naturais diminuindo seu impacto ambiental [10]. A reciclagem de poliéster para produção de outros compósitos com resíduos da indústria textil com espuma de poliuretano e fibras de poliamida também podem ser empregados para produção de mantas de isolamento térmico [11, 12].

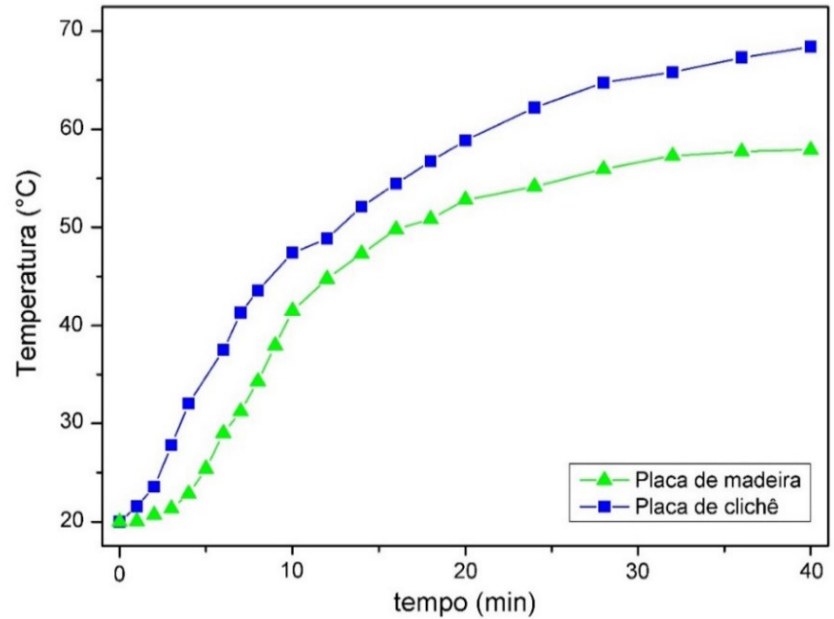

Figura 5: Variação da temperatura em função do tempo em compósitos de clichê reciclado e madeira laminada, colocadas sobre uma placa metálica aquecida a $150{ }^{\circ} \mathrm{C}$. 
A partir dos dados de desempenho mecânico, optou-se por produzir somente os compósitos com PET, devido ao grande número de placas necessárias para realização do teste de isolamento acústico. Os resultados sobre isolamento acústico são apresentados na figura 6. Constatou-se que em frequências menores que $2 \mathrm{kHz}$, ou seja, sons graves a médios, as placas de isolamento não atuaram no isolamento sonoro, sendo a intensidade sonora dentro da cabine com ou sem isolamento parecida em ambos os casos. Por outro lado, em frequência sonoras agudas acima de $2 \mathrm{kHz}$ houve um decréscimo da intensidade sonora de aproximadamente $30 \%$ com o isolamento das placas de clichê. A absorção acústica deve ocorrer por meio da ressonância das ondas sonoras nos poros do material. A faixa de frequência na qual ocorre maior absorção acústica também está ligada ao tamanho do particulado. É importante salientar que, os testes realizados foram comparativos e não seguem normas técnicas.

Materiais porosos ou fibrosos tem sido amplamente utilizados na redução de ruídos por causa de efeitos de ressonância na estrutura interna do material [13]. Elevada absorção acústica são comumente obtidas no âmbito de altas frequências, enquanto que, a absorção acústica em baixas frequências é menor. Isto por causa que, a absorção acústica de compósitos porosos é geralmente determinada pelo tamanho das porosidades [14]. Fibras de poliéster reciclado tem maior absorção acústica com o aumento da espessura das fibras, entretanto, perdem a capacidade de isolamento com o aumento da densidade do material. Este material pode chegar a $90 \%$ de absorção acústica entre $2 \mathrm{kHz}$ e $4 \mathrm{kHz}$ [15]. Compósitos de fibras de poliéster e matriz polipropileno podem fornecer um coeficiente de absorção acústica próxima a 70\% abaixo de $1 \mathrm{kHz}$ [16]. Fibras naturais também tem sido amplamente aplicadas com capacidade de isolamento acústico similar à manta de PET, porém, com a vantagem de serem biodegradáveis [17].

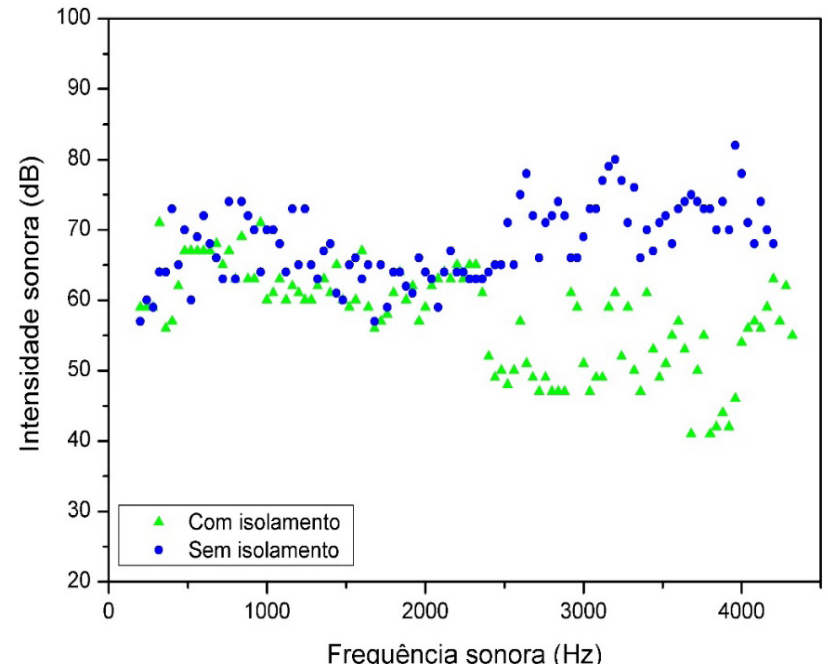

Figura 6: Intensidade sonora medida em função da variação da frequência sonora, dentro de uma cabine com e sem isolamento dos compósitos de clichê reciclado.

\section{CONCLUSÕES}

O principal objetivo deste trabalho foi atingido, ou seja, o desenvolvimento de um método para a produção de placas com clichê reciclado. Os clichês são formados de polímeros elastoméricos, consequentemente, produzir um método de cominuição das placas resilientes em partículas e posterior compactação foi a problemática central. Obteve-se um adequado método de cominuição dos clichês descartados do processo de impressão flexográfica. A partir disso, foi possível produzir placas de compósitos de clichê particulado e PET triturado por prensagem à quente, com adequada flexibilidade e resistência para aplicações com potencial de isolamento acústico e térmico. Este resultado é a principal contribuição deste trabalho e mostra uma importante aplicação para reciclagem dos clichês descartados pela indústria de embalagens, salvaguardando significativos custos do processo de produção e destinação final, aprimorando a gestão ambiental do processo industrial, além de, imensuráveis ganhos ambientais. O compósito produzido apresentou menor capacidade de isolamento térmico que a madeira compensada. Entretanto, aplicou-se condições relativamente severas na caracterização térmica. Desta maneira, o compósito de clichê reciclado ainda apresenta adequada capacidade de isolamento térmico, pois, seu desempenho é próximo ao da madeira. Adicionais teste necessitam ser realizados, como por exemplo, secar o particulado de clichê antes da sua utilização e analisar condições mais branda de variação da temperatura. Uma possível proposta é aplicar o compósito na construção civil. Os testes de isolamento acústico do compósitos produzidos a partir de clichê reaproveitado indicaram uma potencial aplicação neste sentido. Pode-se considerar todavia, que o material dos clichês deve proporcionar propriedades superiores quanto à absorção por impacto devido à sua elevada resiliência, podendo ser aplicado no isolamento de 
pisos, dada a obtenção um compósito com elevada flexibilidade. Além disso, verificou-se a necessidade de realizar testes acerca da inflamabilidade dos compósitos para aplicação na construção civil. Novas composições com adição de argilas ou compostos de fósforo poderiam ser produzidas para avaliação da inflamabilidade. A adição destes reforços, deve auxiliar também a capacidade de isolamento térmico.

\section{AGRADECIMENTOS}

Os autores gentilmente agradecem à FAPESC e ao IFSC pelo financiamento das atividades e incentivo para o desenvolvimento sustentável.

\section{BIBLIOGRAFIA}

[1] SIRKIN, T., HOUTEN, M. "The cascade chain: A theory and tool for achieving resource sustainability with applications for product design.” Resources, Conservation and Recycling, v. 10, pp. 213, 1994.

[2] ZANIN, M., MANCINI, S.D. Resíduos plásticos e reciclagem. 2 ed. São Carlos: EdUSFCar, 2009.

[3] PIVA, A.M., WIEBECK, H. Reciclagem do plástico. São Paulo: Artliber, 2004.

[4] CÁRIO, S.A.F., et al. Arranjos Produtivos de Transformados Plásticos das Regiões Nordeste e Sul: Programa Estratégico de Desenvolvimento Produtivo com Base em Inovação. Florianópolis: UFSC/Governo do Estado de Santa Catarina, 2005.

[5] ASSOCIAÇÃO BRASILEIRA DA INDÚSTRIA DE PLÁSTICOS. Perfil, 2015.

[6] SCARPETA, E. Flexografia: Manual Prático. São Paulo: Bloco Comunicacão Ltda, 2007.

[7] WIEST, M., et al. Flexography: Principles and Practices. 5 ed. New York: Foundation of Flexography Technical Association, 1999.

[8] SOMMERHUBER, P.F., et al. "Life cycle assessment of wood-plastic composites: Analyzing alternative materials and identifying an environmental sound end-of-life option." Resources, Conservation and Recycling, v. 117, pp. $235,2017$.

[9] INGRAO, C., et al. "Recycled-PET fibre based panels for building thermal insulation: Environmental impact and improvement potential assessment for a greener production." Science of the Total Environment, v. 493, pp. 914, 2014.

[10] PATNAIK, A., et al. "Thermal and sound insulation materials from waste wool and recycled polyester fibers and their biodegradation studies.” Energy and Buildings, v. 92, pp. 161, 2015.

[11] MARQUES, D.V., et al. "Recycled polyethylene terephthalate-based boards for thermal acoustic insulation." Journal of Cleaner Production, v. 189, pp. 251, 2018.

[12] DISSANAYAKE, D.G.K., et al. "Developing a compression moulded thermal insulation panel using postindustrial textile waste". Waste Management, v. 79, pp. 356, 2018.

[13] KINO, N., UENO, T. "Evaluation of acoustical and non-acoustical properties of sound absorbing materials made of polyester fibres of various cross-sectional shapes." Applied Acoustics, v. 69, pp. 575, 2008.

[14] WANG, C.N., TORNG, J.H. "Experimental study of the absorption characteristics of some porous fibrous materials." Applied Acoustics, v. 62, pp. 447, 2001.

[15] SEDDEQ, H.S., et al. "Investigation on sound absorption properties for recycled fibrous materials." Journal Industrial Textiles, v. 43, pp. 56, 2013.

[16] LOU, C.W., LIN, J.H., SU, K.H. "Recycling polyester and polypropylene nonwoven selvages to produce functional sound absorption composites.” Textile Research Journal, v. 75, pp. 390, 2005.

[17] BERARDI, U., IANNACE, G. "Predicting the sound absorption of natural materials: best-fit inverse laws for the acoustic impedance and the propagation constant." Applied Acoustics, v. 115, pp.131, 2017.

\section{ORCID}

Eduardo do Nascimento

Elton Maciel http://orcid.org/0000-0001-8247-3976

http://orcid.org/0000-0002-7311-3650 